\title{
Electrochemical synthesis of calcium carbonate coatings on stainless steel substrates
}

\author{
M. Dinamani ${ }^{\mathrm{a}}$, P. Vishnu Kamath ${ }^{\mathrm{a},{ }^{*}}$, R. Seshadri ${ }^{\mathrm{b}}$ \\ ${ }^{a}$ Department of Chemistry, Central College, Bangalore University, Bangalore 560001, India \\ ${ }^{\mathrm{b}}$ Solid State and Structural Chemistry Unit, Indian Institute of Science, Bangalore 560012, India \\ (Refereed)
}

Received 10 September 2001; accepted 14 January 2002

\begin{abstract}
Calcite $\mathrm{CaCO}_{3}$ has been electrocrystallized on stainless steel substrates by the galvanostatic cathodic reduction of aqueous calcium bicarbonate solutions. The deposition is controlled by $\mathrm{pH}$ changes occurring close to the cathode due to electrogeneration of base. The deposit morphology varies from facetted rhombs observed at low $\left(1-20 \mathrm{~mA} \mathrm{~cm}^{-2}\right.$ ) current densities to corner-rounded particles observed at high $\left(40 \mathrm{~mA} \mathrm{~cm}^{-2}\right)$ current densities. (C) 2002 Elsevier Science Ltd. All rights reserved.
\end{abstract}

Keywords: A. Inorganic compounds; C. X-ray diffraction

\section{Introduction}

Calcium carbonate $\left[\mathrm{CaCO}_{3}\right]$ is an important, naturally occurring inorganic biomaterial [1]. Besides an amorphous form [2], $\mathrm{CaCO}_{3}$ is known to crystallize in three polymorphic modifications viz., calcite, aragonite and vaterite [3-5]. Of these, calcite is the thermodynamically stable phase [4,5]. Nevertheless, different organisms deposit $\mathrm{CaCO}_{3}$ in different modifications depending upon the structural and functional application of the material. Besides polymorphism, $\mathrm{CaCO}_{3}$ biodeposits exhibit variation in crystal size, shape, morphology, texture and aggregation. Designing an in vitro technique to mimic nature's fine control over the crystallization process is one of the contemporary concerns of materials chemistry. The use of additives to exercise

\footnotetext{
${ }^{*}$ Corresponding author. Tel.: +91-80-2211-679; fax: +91-80-360-1310.

E-mail address: vishnu@sscu.iisc.ernet.in (P.V. Kamath).
} 
control over crystal growth of $\mathrm{CaCO}_{3}$ by processes of molecular recognition has been reported in the literature [2-10].

Electrochemical synthesis has many features in common with additive/templatemediated synthesis. The electrode itself acts as a template on which crystallization of the solid phase takes place and the electric double layer can, in principle, direct growth. However, there are not many instances to support this premise. $\mathrm{Xu}$ et al. [11] have electrodeposited $\mathrm{CaCO}_{3}$ on single crystal $\mathrm{Si}$ and polycrystalline $\mathrm{Ni}$ surfaces and studied the crystallization of calcite $\mathrm{CaCO}_{3}$ under potentiostatic conditions. At high temperatures and in the presence of dissolved $\mathrm{Mg}^{2+}$ ions, $\mathrm{CaCO}_{3}$ deposits as aragonite rather than the usual calcite. These results are by themselves not surprising and are observed during bulk crystallization from solution [12]. However, what is significant is the observation of a thin oriented $\mathrm{CaCO}_{3}$ film [with the $\left(\begin{array}{ll}1 & 0\end{array}\right)$ face parallel to the substrate] at short deposition times, followed by the growth of a thick film with loss of orientation at long deposition times.

To obtain a deeper understanding into the electrodeposition of $\mathrm{CaCO}_{3}$, we report, in this paper, the controlled galvanostatic deposition of $\mathrm{CaCO}_{3}$ on stainless steel substrates. Galvanostatic synthesis affords a constant rate of deposition and permits the evaluation of such parameters as Coulombic efficiencies. While the range of electrodeposition conditions employed in this study yielded only calcite $\mathrm{CaCO}_{3}$, the deposit morphology could be controlled by varying the deposition current.

\section{Experimental}

All the solutions used in this study were prepared using ion-exchanged (Barnstead Easypure $^{\mathrm{TM}}$ ) water. Prior to electrodeposition, all the stainless steel (SS) flag electrodes were degreased and electrochemically polished as described elsewhere [13].

Equal volumes of $0.015 \mathrm{M} \mathrm{Ca}\left(\mathrm{NO}_{3}\right)_{2}$ (Analar grade, s.d. fiNE CHEM, India) and $0.03 \mathrm{M} \mathrm{NaHCO}_{3}$ (Analar grade, Merck, India) solutions were mixed and allowed to stand in a scratch-free beaker for $24 \mathrm{~h}$ under ambient conditions to ensure there was no chemical precipitation of $\mathrm{CaCO}_{3}$ on aging, as such precipitation would compromise the results of electrochemical synthesis. The solution concentration chosen is below the $\mathrm{CaCO}_{3}$ supersaturation and no chemical precipitation is expected. In test experiments, similarly prepared solutions were electrolyzed using a SS 304 flag (area, $4.5 \mathrm{~cm}^{2}$ ) as cathode and a Pt mesh electrode (geometrical area, $28 \mathrm{~cm}^{2}$ ) as the anode. A saturated calomel electrode was used as a reference. Electrodeposition was carried out at various current densities (1-40 $\mathrm{mA} \mathrm{cm}^{-2}$ ) for times varying from 10 to $120 \mathrm{~min}$ using a EG\&G PARC Versastat II A potentiostat operated in galvanostatic mode. At the end of the experiment, white crystallites could be seen growing on the surface of the cathode. By weighing the cathode before and after deposition, the coating weight could be monitored over a wide range of deposition conditions.

Powder X-ray diffraction (PXRD) data were obtained by directly mounting the electrode coated with $\mathrm{CaCO}_{3}$ on a Seimens D5005 diffractometer operated in a reflection geometry. Data were collected using $\mathrm{Cu} \mathrm{K} \alpha$ radiation using a continuous 
scan rate of $1^{\circ}$ per minute $(2 \theta)$ or less and were then binned into $2 \theta$ steps of $0.02^{\circ}$. All PXRD profiles were fitted by the Rietveld method as implemented in the XND Rietveld code (version 1.20) [14] using the published structure of calcite [6]. The stainless steel substrate gave rise to three Bragg peaks in the $2 \theta$ range of interest at 43.6, 44.4 and $50.6^{\circ}$, respectively. These could each be fitted as a sum of a Gaussian and a Lorentzian peak. Infrared spectra were recorded using a Nicolet Model Impact 400 D FT-IR Spectrometer ( $\mathrm{KBr}$ pellets, $4 \mathrm{~cm}^{-1}$ resolution). Scanning electron micrographs were obtained using a Jeol JSM 5600 LV microscope directly from the coating on the substrate by mounting small pieces of the electrode on conducting carbon tape and sputter coating with gold to improve conductivity.

\section{Results and discussion}

$\mathrm{CaCO}_{3}$ is normally obtained from a supersaturated solution of $\mathrm{Ca}\left(\mathrm{HCO}_{3}\right)_{2}$ by allowing either the rapid or slow evaporation of $\mathrm{CO}_{2}$. This is done by either heating or by $\mathrm{pH}$ control according to the reaction

$$
\mathrm{Ca}^{2+}+\mathrm{HCO}_{3}^{-}+\mathrm{OH}^{-} \rightarrow \mathrm{CaCO}_{3} \downarrow+\mathrm{H}_{2} \mathrm{O}
$$

Electrogeneration of base by cathodic reduction of aqueous solutions of metal nitrates, provides an electrochemical route to exercise delicate control over the solution $\mathrm{pH}$ by a number of reactions $[15,16]$. Most prominent among these are the nitrate reduction reaction:

$$
\mathrm{NO}_{3}{ }^{-}+\mathrm{H}_{2} \mathrm{O}+2 \mathrm{e} \rightarrow \mathrm{NO}_{2}{ }^{-}+2 \mathrm{OH}^{-}, \quad E^{\circ}(\text { vs. } \mathrm{NHE})=0.01 \mathrm{~V}
$$

and the electrolysis of water:

$$
2 \mathrm{H}_{2} \mathrm{O}+2 \mathrm{e} \rightarrow \mathrm{H}_{2}+2 \mathrm{OH}^{-}, \quad E^{\circ}(\text { vs. NHE})=-0.83 \mathrm{~V}
$$

The variation in cell potential during galvanostatic deposition of $\mathrm{CaCO}_{3}$ at low (1$5 \mathrm{~mA} \mathrm{~cm}^{-2}$ ) currents is shown in Fig. 1. The observed deposition potentials far

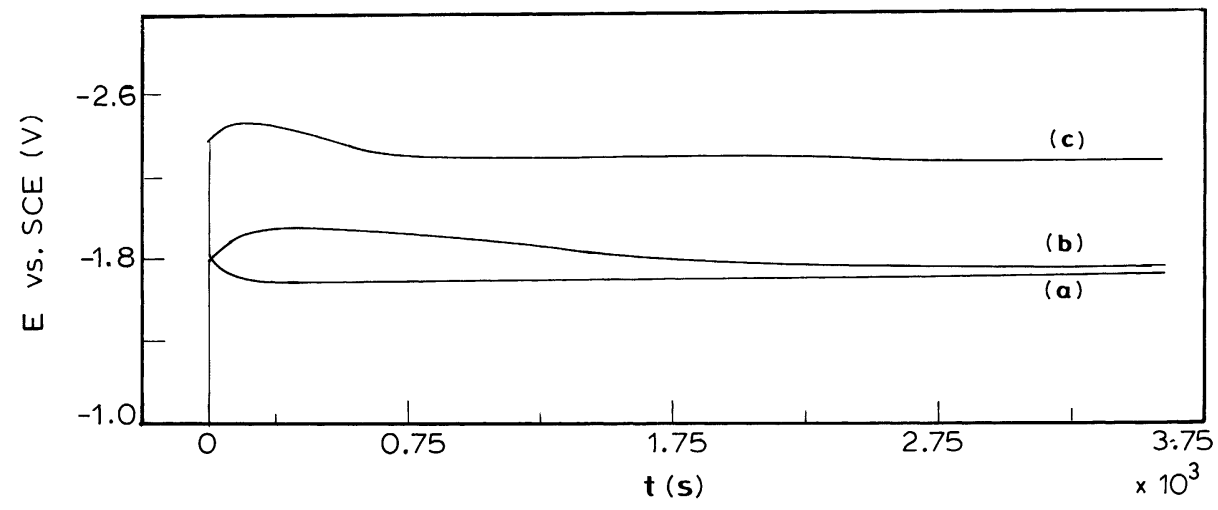

Fig. 1. Variation in cell potential with time during the electrodeposition of $\mathrm{CaCO}_{3}$ coatings at (a) $1 \mathrm{~mA} \mathrm{~cm}^{-2}$; (b) $2 \mathrm{~mA} \mathrm{~cm}^{-2}$; (c) $5 \mathrm{~mA} \mathrm{~cm}^{-2}$ current density, respectively. 


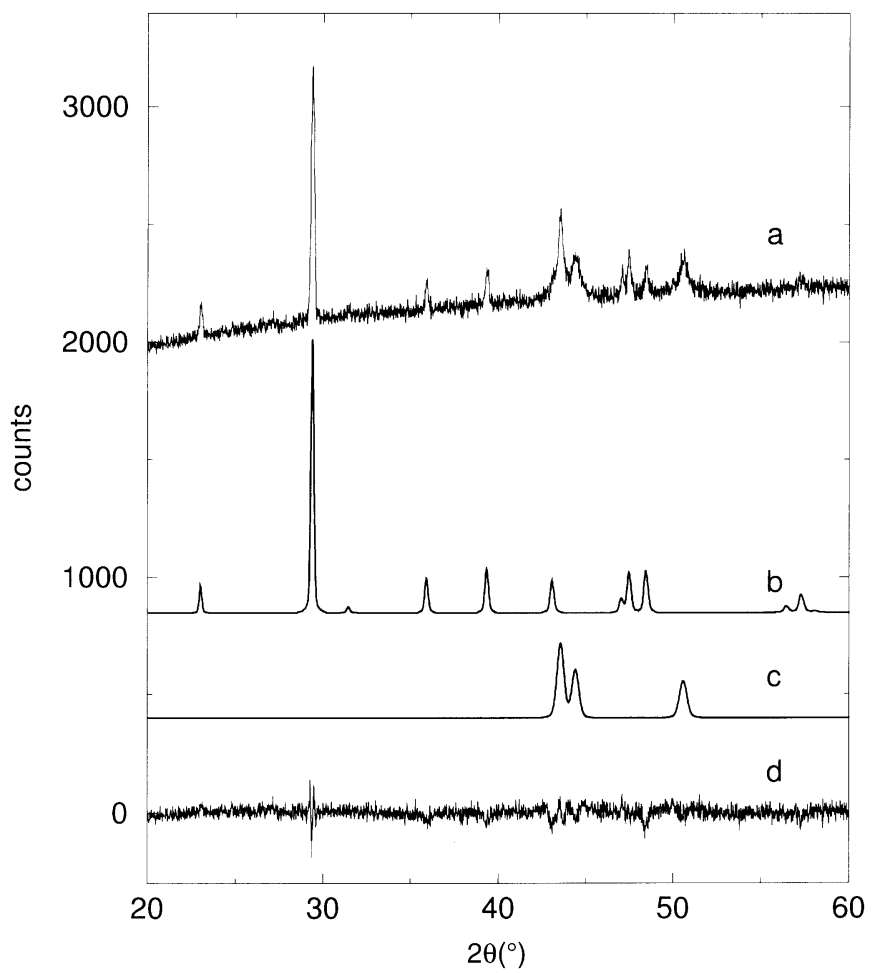

Fig. 2. (a) Powder X-ray diffractogram of a $\mathrm{CaCO}_{3}$ coating (deposition current, $5 \mathrm{~mA} \mathrm{~cm}^{-2}$ time, $1 \mathrm{~h}$ ) compared with (b) Rietveld fit, (c) contribution of the stainless steel substrate and (d) error function.

exceed that required for the electrolysis of water. Combined with the fact that the nitrate activity in the baths used by us is low $(\leq 0.015 \mathrm{M})$, it appears that reaction (c) is the main contributing factor to electrogeneration of base in the present system.

In an electrochemical cell, the generation of $\mathrm{OH}^{-}$ions and the consequent increase in $\mathrm{pH}$ occurs close to the cathode, resulting in the electrodeposition of $\mathrm{CaCO}_{3}$ on the electrode surface by reaction (a).

In Fig. 2 is shown a typical powder X-ray diffractogram of a coating obtained at $5 \mathrm{~mA} \mathrm{~cm}{ }^{-2}$ (time, $1 \mathrm{~h}$ ). This and other patterns recorded for coatings obtained under different conditions can be assigned to an unoriented growth of the calcite phase by the Rietveld refinement procedure. A typical infrared spectrum is shown in Fig. 3. The appearance of characteristic vibrations at 717,875 and $1426 \mathrm{~cm}^{-1}$ indicates the deposit to comprise purely of calcite $\mathrm{CaCO}_{3}$. This rules out the possibility of formation of the other modifications even in small proportions below the levels of sensitivity of powder diffraction.

$\mathrm{Xu}$ et al. [11] have also reported the electrochemical synthesis of $\mathrm{CaCO}_{3}$ under potentiostatic conditions by selecting the oxygen reduction reaction for the electrogeneration of base. These conditions also led to the deposition of phase-pure calcite. The cell currents used were low $\left(<0.4 \mathrm{~mA} \mathrm{~cm}^{-2}\right)$ compared to those used in the 


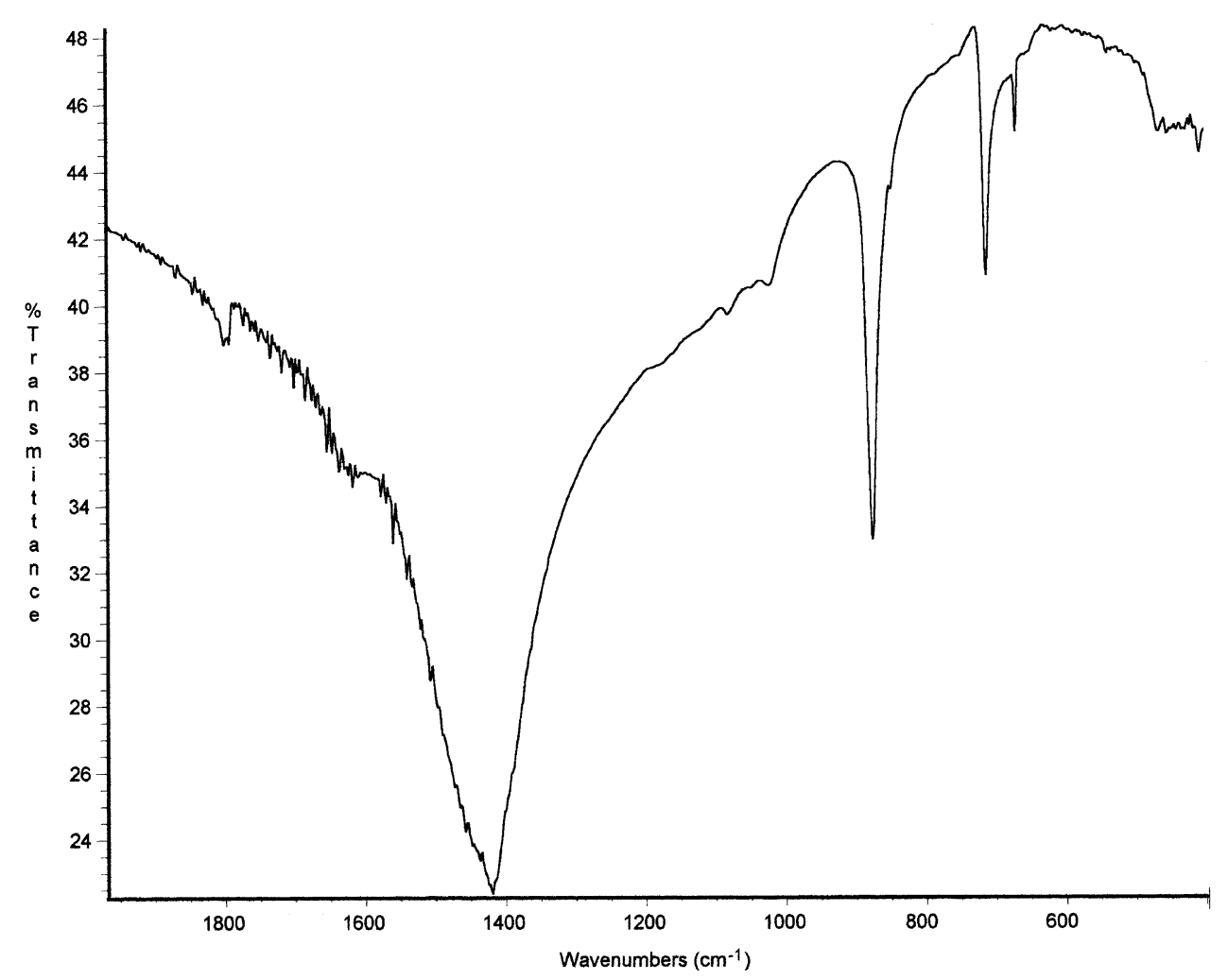

Fig. 3. IR spectrum of a typical electrodeposited sample of $\mathrm{CaCO}_{3}$.

present study. Thereby they have investigated the low thickness regime, which reveals an oriented growth of calcite crystallites.

The morphology of the deposits obtained under different conditions is shown in Fig. 4. In keeping with the results of Xu et al. [11], the deposit is not uniform and the bare stainless steel surface can be seen, with only a few $\mathrm{CaCO}_{3}$ crystals sprinkled on the surface. The crystallites exhibit a rhomboidal shape with sharply defined corners. The crystallites are 3-8 $\mu \mathrm{m}$ in size. However at high $\left(40 \mathrm{mAh} \mathrm{cm}{ }^{-2}\right)$ values of charge, the corners of the rhomboidal crystallites are rounded off. In all crystallites, the corner pointing away from the electrode is sharp, while the corners pointing towards the electrode surface are rounded. The surface of the crystallites proximal to the electrode have been pitted and roughened. This rounding of the corners and the pitting of surfaces is characteristic of redissolution of the crystallites. Xu et al. [11] have obtained corner-rounded crystallites by incorporation of $\mathrm{Mg}^{2+}$ ions in the deposit. Mg-containing calcites have a higher solubility than pure calcites.

The dissolution at high current densities is due, to the high rate of base generation near the electrode surface, which produces a high local $\mathrm{pH}$. This together with depletion of free $\mathrm{Ca}^{2+}$ owing to the deposition of $\mathrm{CaCO}_{3}$ produces $\mathrm{Ca}^{2+}$ undersaturation in the region close to the electrode. This undersaturation is not adequately compensated by $\mathrm{Ca}^{2+}$ diffusion from the bulk as diffusion is a slow process. The 
(a)

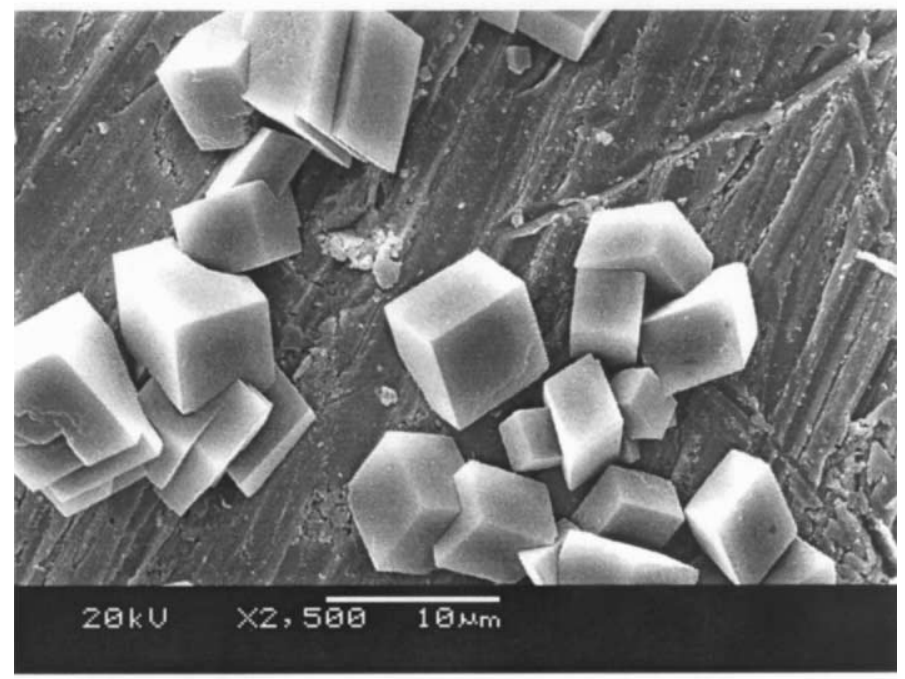

(b)

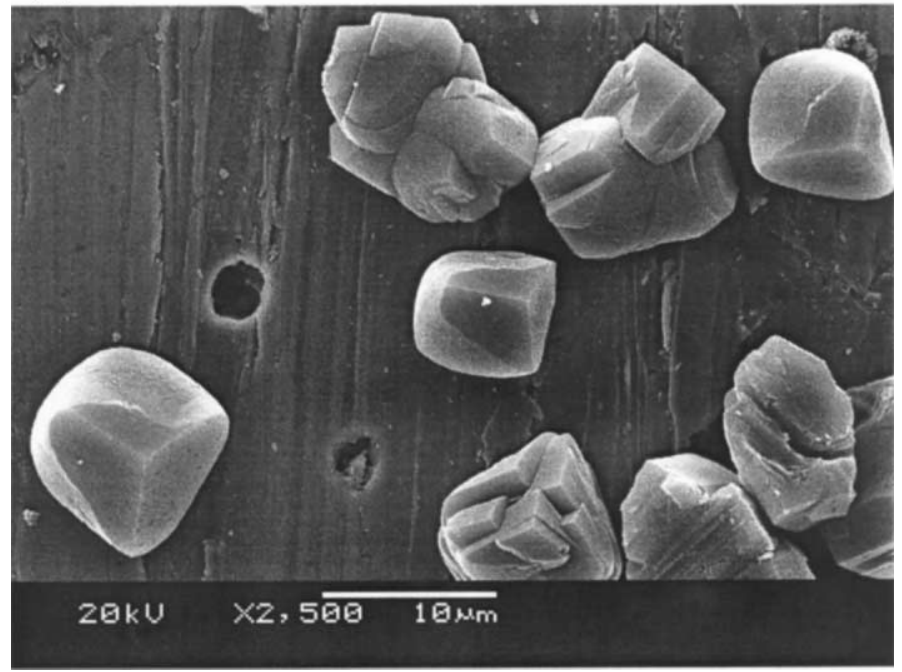

Fig. 4. Scanning electron micrographs of $\mathrm{CaCO}_{3}$ electrocrystallized at (a) $5 \mathrm{~mA} \mathrm{~cm}^{-2}$ and (b) $40 \mathrm{~mA} \mathrm{~cm}^{-2}$.

undersaturation causes redissolution of the crystallites from the end proximal to the electrode surface. In this manner, a periodic oscillation of the $\mathrm{Ca}^{2+}$ concentration is expected in the region close to the electrode surface. This is reflected in the periodic oscillation in the cell potential during deposition at high current densities (see Fig. 5). Other authors [17] have also attributed similar oscillations to deposition-dissolution phenomena in other systems. The alternative explanation invoking the deposition of an insulating layer followed by dielectric breakdown advanced by Switzer et al. [18] 


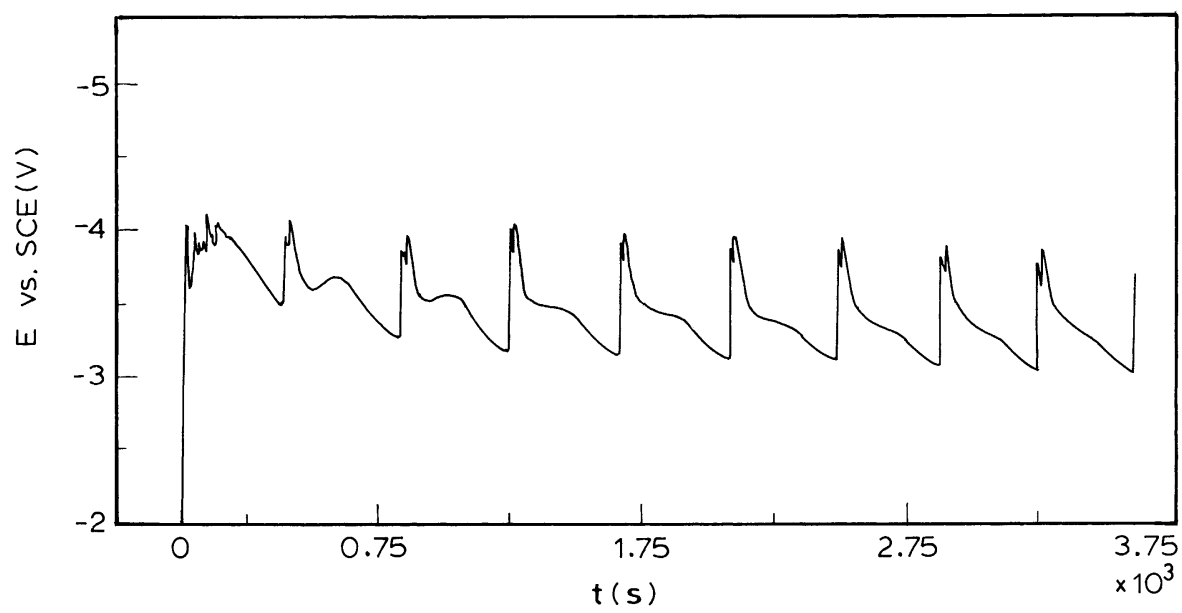

Fig. 5. Periodic oscillation in cell potential during the deposition of $\mathrm{CaCO}_{3}$ at $40 \mathrm{~mA} \mathrm{~cm}^{-2}$.

is not valid in the present context, as the electrodeposited $\mathrm{CaCO}_{3}$ film is not continuous and the bare electrode is always in contact with the electrolyte.

In template-mediated syntheses, growth-directing effects of the template promote strongly oriented films. When the template is polycrystalline, as in the present instance, there is less likelihood of any coherent structure directing influence of the substrate. Nevertheless, use of electrochemistry has resulted in the oriented growth of $\mathrm{Cu}_{2} \mathrm{O}$ [19], $\mathrm{BaSO}_{4}$ [20], and $\mathrm{Pb}-\mathrm{Tl}$-oxide [21] thin films even on polycrystalline stainless steel substrates. We believe that this kind of oriented crystal growth has less to do with the substrate than with the kinetics of deposition, which in turn is controlled by the extent of supersaturation of the reactant species. Supersaturation is itself controlled by the $\mathrm{pH}$, which is varied electrochemically. We believe that morphological changes observed in our studies as a result of current density are a result of a complex interplay between the competing solubilities of $\mathrm{Ca}(\mathrm{OH})_{2}-\mathrm{CaCO}_{3}-$ $\mathrm{Ca}\left(\mathrm{HCO}_{3}\right)_{2}$ in solution. With $\mathrm{pH}$ variation these phases can deposit and redissolve, producing morphological variations.

Galvanostatic deposition enables the direct measurement of the coating growth characteristics and Coulombic efficiencies. In Fig. 6, are plotted the coating weight as a function of deposition time, bath concentration and the current density. The amount of electrogenerated $\mathrm{CaCO}_{3}$ is expected to increase with the amount of charge passed, $Q$, computed as current $\times$ time. $Q$ can be increased by either increasing the time (duration of the deposition) or the current density. The coating weight is found to increase with deposition time and reach a limiting value (see Fig. 6a). The Coulombic efficiency (estimated as the moles of $\mathrm{CaCO}_{3}$ per Coulomb of charge passed) is approximately $15 \%$, indicating that a majority of the electro-generated hydroxyl ions remain dissolved in water owing to the high solubility of $\mathrm{Ca}(\mathrm{OH})_{2}$. However, on increasing the current density, the coating weight does not exhibit any increase (Fig. 6b) and consequently there is a sharp drop in the Coulombic efficiency from $15 \%$ at $2 \mathrm{~mA} \mathrm{~cm}^{-2}$ to less than $6 \%$ at $5 \mathrm{~mA} \mathrm{~cm}^{-2}$. We attribute this decrease to (1) 

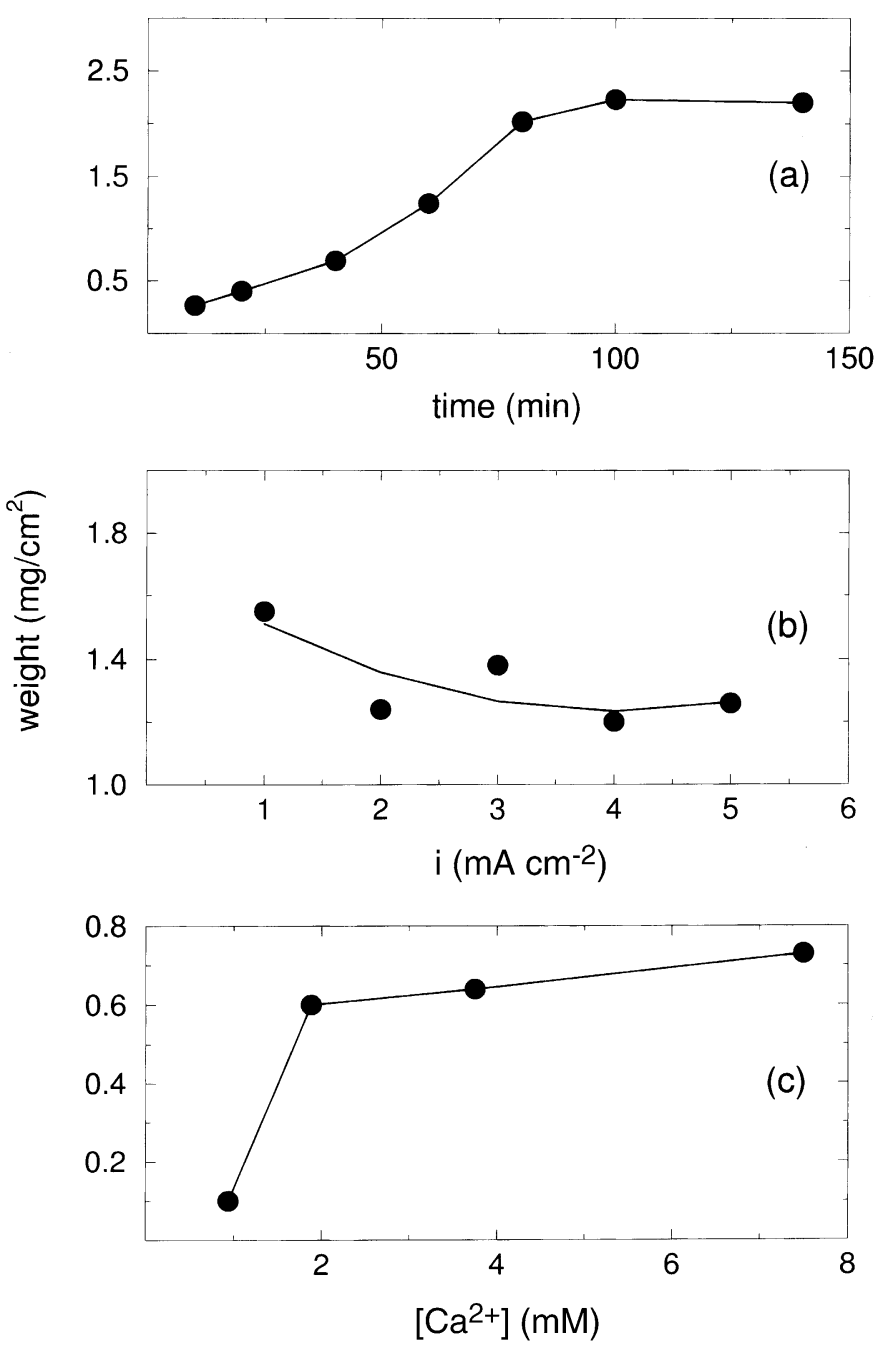

Fig. 6. Coating growth as a function of (a) time (bath concentration, $7.5 \mathrm{mM}$ in $\mathrm{Ca}^{2+}$, current density, $5 \mathrm{~mA} \mathrm{~cm}^{-2}$ ); (b) current density (bath concentration, $7.5 \mathrm{mM}$ in $\mathrm{Ca}^{2+}$, time, $1 \mathrm{~h}$ ) and (c) bath concentration (current density, $5 \mathrm{~mA} \mathrm{~cm}^{-2}$, time $1 \mathrm{~h}$ ).

various parasitic reactions, and (2) to the solubility of $\mathrm{CaCO}_{3}$ in high $\mathrm{pH}$ conditions. On increasing the bath concentration, the electrogenerated $\mathrm{CaCO}_{3}$ increases and reaches a limiting value (Fig. 6c), although the limiting thickness achieved under different deposition conditions are different.

\section{Acknowledgments}

The authors thank the Department of Science and Technology, Government of India for financial support through grants awarded to P.V.K. and R.S. 


\section{References}

[1] S. Mann, Chemistry \& Industry, 6 February 1995, p. 93; S. Mann, J. Mater. Chem. 5 (1995) 935.

[2] J.J.M. Donners, B.R. Heywood, E.W. Meijer, R.J.M. Nolte, C. Roman, A.P.H.J. Schenning, N.A.J.M. Sommerdijk, Chem. Commun. (2000) 1937.

[3] G. Falini, S. Albeck, S. Weiner, L. Addadi, Science 271 (1996) 67.

[4] D. Chakrabarty, S. Mahapatra, J. Mater. Chem. 9 (1999) 2953.

[5] K. Naka, D.-K. Keum, Y. Tanaka, Y. Chujo, Chem. Commun. (2000) 1537.

[6] R.J. Hill, Can. Mineralogist 15 (1977) 522, Inorganic Crystal Structure Database Entry 100676.

[7] S. Mann, B.R. Heywood, S. Rajam, J.D. Birchal, Proc. R. Soc. (Lond.) A423 (1989) 457.

[8] G. Falini, S. Fermani, M. Gazzano, A. Ripamonti, Chem. Eur. J. 3 (1997) 1807.

[9] J. Kuther, R. Seshadri, G. Nelles, W. Assenmacher, H.-J. Butt, W. Mader, W. Tremel, Chem. Mater. 11 (1999) 1317.

[10] S. Mann, G.A. Ozin, Nature 382 (1996) 313.

[11] S. Xu, C.A. Melendres, J.H. Park, M.A. Kamrath, J. Electrochem. Soc. 146 (1999) 3315.

[12] J.L. Wray, F. Daniels, J. Am. Chem. Soc. 79 (1957) 2031;

R.K. Given, B.H. Wilkinson, J. Sedim. Petrol. 55 (1985) 109.

[13] D.A. Corrigan, R.M. Bendert, J. Electrochem. Soc. 136 (1989) 723.

[14] Programme XND, J.-F. Bérar, ESRF, Grenoble, France. More information under: http:// www.ccp14.ac.uk;

J.-F. Bérar, in: Proceedings of the IUCr Satellite Meeting on Powder Diffractometry, Toulouse, France, July 1990;

J.-F. Bérar, P. Garnier, in: Proceedings of the II APD Conference, NIST (US), Gaithersburg, MA, May 1992;

J.-F. Bérar, P. Garnier, NIST Special Publication 846 (1992) 212.

[15] G.H.A. Therese, P.V. Kamath, Chem. Mater. 12 (2000) 1195.

[16] I. Zhitomirsky, Am. Cerm. Soc. Bull. September (2000) 57.

[17] B. Rush, J. Newman, J. Electrochem. Soc. 142 (1995) 3770.

[18] J.A. Switzer, C.-J. Hung, L.-Y. Huang, E.R. Switzer, D.R. Kammler, T.D. Golden, E.W. Bohannan, J. Am. Chem. Soc. 120 (1998) 3530.

[19] T.D. Golden, M.G. Shumsky, Y. Zhou, R.A. VanderWerf, R.A. Van Leeuwen, J.A. Switzer, Chem. Mater. 8 (1996) 2499.

[20] M. Dinamani, P.V. Kamath, R. Seshadri, Chem. Mater. 13 (2001) 3981.

[21] J.A. Switzer, M.J. Shane, R.J. Phillips, Science 247 (1990) 444. 